\title{
Preparation of infertile male rabbits by local electron beam irradiation for intratesticular transplantation of autologous bone marrow stem cells
}

\author{
Xin-Hong Zhao', Jian-Hong Qiu", Wen-Qing Cai'II, Song Li" ${ }^{\mathrm{IV}}$, Wei Li ${ }^{\mathrm{V}}$ \\ IMaster, Associate Professor, Department of Urology, Second Hospital of Heibei Medical University, Shijiazhuang, China. Main author. \\ IIFull Professor, Department of Urology, Bethune International Peace Hospital, Shijiazhuang, China. Design of the study.

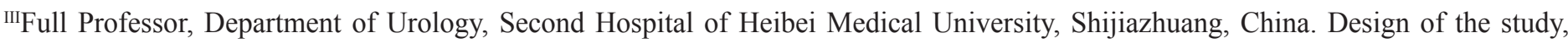 \\ critical revision.

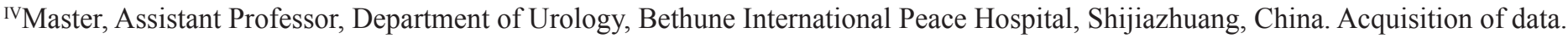 \\ ${ }^{\vee}$ Full Professor, Department of Urology, Second Hospital of Heibei Medical University, Shijiazhuang, China. Analysis and interpretation \\ of data.
}

\section{ABSTRACT}

PURPOSE: To explore an efficient and safe protocol for the preparation of infertile male rabbits from which bone marrow stem cells (BMSCs) could be isolated and cultured.

METHODS: Autologous BMSCs could be used for intratesticular transplantation and male infertility research. For this model, various doses (e.g., 6, 8, 10, or $12 \mathrm{~Gy}$ ) of electron beam irradiation from a linear accelerator were locally applied to the scrotum of 5-month-old male New Zealand white rabbits. The effects of irradiation were compared between treatment groups, and with age-matched normal controls. Both morphology and hollow ratios of seminiferous tubules (HRST) were examined two, four, six, eight and 12-weeks postirradiation.

RESULTS: The seminiferous epithelium showed varying degrees of damage in all treatment groups compared with unirradiated controls, yet Sertoli and Leydig cells appeared unaffected. A dose-dependent response in spermatogenesis was also observed. BMSCs that were isolated and cultured from rabbits of the normal control group and the 12 Gy treatment group were compared with respect to morphology and growth. Starting at 6 weeks, HRST of the 12 Gy-treatment group were stable, and were the highest among all the groups. BMSCs from rabbits treated with 12 Gy also exhibited similar growth as the control group.

CONCLUSION: Local dose of 12 Gy to the testes of 5-month-old male New Zealand rabbits is a protocol with which to obtain autologous bone marrow stem cells.

Key words: Infertility. Radiotherapy. Cell Transplantation. Testis. Rabbits. 


\section{Introduction}

Infertility is a major medical problem worldwide, with male factors being the sole, or effective cause in more than $40 \%$ of cases ${ }^{1}$. Moreover, of these cases, approximately $50 \%$ result from defective spermatogenesis due to complete blockage of spermatogenesis, low sperm counts, or abnormal sperm motility, morphology, or function ${ }^{2}$. Although infertility is often bypassed using assisted reproductive technologies (ART), some of these methods are associated with safety or ethical concerns ${ }^{3}$. For example, spermatogonial stem cell transplantation (SSCT) is a type of ART that was first demonstrated in a mouse model ${ }^{4}$, and involves donor-derived spermatogenesis in the recipient mouse testis. This model established that the donor haplotype is passed on to offspring by recipient animals, and is associated with ethical issues.

Some report has suggested that adult bone marrowderived stem cells (BMSCs) are able to regenerate various non-hematopoietic cell lineages in several organs, and that tissue-specific and pluripotent stem cells are present in the bone marrow $^{5}$. As for male germinal lineages, mouse adult bone marrow mesenchymal stem cells that have been grown in vitro in the presence of retinoic acid have been found to express germ cell markers, yet fail to undergo spermatogenesis following transplantation into testes ${ }^{6}$. A similar transdifferentiation process was described for adult human bone marrow cells ${ }^{7}$. In work by another group, BMSCs were shown to differentiate into putative germ cells in mice following transplantation in testis ${ }^{8}$. However, the recipients that underwent allo- or hetero-transplantation were not compatible with an autotransplantation strategy involving bone marrow stem cell-derived germline cells. Therefore, in the present study, a protocol to prepare male sterile rabbits was tested in order to provide a valuable model for intratesticular transplantation using autologous BMSCs.

\section{Methods}

Male, New Zealand White rabbits ( $\mathrm{n}=30)$, approximately 5-months-old, were purchased from the Experimental Animal Center of Hebei Medical University (Shijiazhuang, China). These rabbits were maintained in a controlled environment with access to food and water. Handling of the animals was approved by the Care of Experimental Animals Committee of Hebei Medical University and was in compliance with the National Research Council's guidelines. Rabbits were randomly divided into five groups, including experimental groups A-D. Testes were irradiated with single doses of $6,8,10$, and 12 Gy, respectively, and untreated rabbits served as a control group (E). For each group, 12 testes were evaluated.

\section{Electron beam irradiation}

Prior to irradiation, animals were anesthetized with an intramuscular injection of ketamine $(50 \mathrm{mg} / \mathrm{kg}) /$ xylazine $(10$ $\mathrm{mg} / \mathrm{kg}$ ). Rabbits of the experimental groups (A-D) then received irradiation directly to both testes from a 6-mV electron beam using a linear accelerator (Varian, USA) at a mean dose rate of $2 \mathrm{~Gy} / \mathrm{min}$. A lead plate with a $3.8-\mathrm{cm}$ diameter hole was used to collimate the beam to irradiate both testes while minimizing exposure to surrounding tissues. For the control untreated group, each rabbit was placed on the handling table for 2 minutes without receiving irradiation.

\section{Testes collection and histopathologic evaluation}

At two, four, six, eight and 12 weeks after treatment, one rabbit from each study group was anesthetized prior to undergoing a bilateral orchiectomy. Briefly, the testes were halved along the longitudinal axis, fixed immediately in Bouin's solution, and embedded in paraffin. After routine sectioning and staining with hematoxylin and eosin, sections were examined to observe meiotic cells and to determine the stage of spermatogenesis in at least 400 seminiferous tubule cross sections per testis. Seminiferous tubules that had no any spermatogenesis were regarded as hollow. A ratio of hollow seminiferous tubules (RHSTs) to total seminiferous tubules was then calculated based on the percentage of tubules that were observed to be hollow following apoptosis by spermatogenic cells. Images were captured using an optical microscope.

Isolation, culture, and observation of BMSC proliferation

Isolation of BMSCs was performed as described previously 9 . Briefly, under anesthesia, the left leg was shaved, disinfected, and bone marrow (3.0-4.0 ml) was collected from the intumescence of the proximal tibia using a 12-gauge puncture needle with a $5 \mathrm{ml}$ syringe containing $1 \mathrm{ml}$ heparin $(5000 \mathrm{U} / \mathrm{ml})$. Bone marrow collected was diluted 1:2 with phosphate buffered saline (PBS), and the same volume of Percoll lymphocyte separation solution $(1.073 \mathrm{~g} / \mathrm{ml})$ was added. This mixture of heparin and bone marrow was centrifuged at 2,000 r/min for $25 \mathrm{~min}$. The mononuclear fraction interphase was collected and washed twice in PBS. The final pellet was resuspended in $3 \mathrm{ml}$ 
DMEM supplemented with $15 \%$ fetal bovine serum (FBS), antibiotics (penicillin G, $100 \mathrm{U} / \mathrm{ml}$; streptomycin, $0.1 \mathrm{mg} / \mathrm{ml}$ ), and seeded in $25 \mathrm{~cm}^{2}$ culture flasks and cultured at $37^{\circ} \mathrm{C}$ under a $5 \%$ $\mathrm{CO}_{2}$ atmosphere. Every $48 \mathrm{~h}$, the medium was changed, and nonadherent hematopoietic cells were removed. When cells were close to confluence, $0.25 \%$ trypsin $/ 0.02 \%$ ethylenediamine tetraacetic acid (EDTA) was added for passaging. Using an inverted microscope, the morphology of rabbit MSCs was observed. After three passages, BMSCs were seeded in 24-well plates with $2 \times 10^{4}$ cells/well plated in triplicate. Cells were collected from each well 1-7 days after seeding and were counted to produce cell growth curves.

\section{Statistical analysis}

Data are expressed as the mean \pm standard deviation (SD). All statistical analyses were performed using SPSS 11.5. Data were analyzed using one-way analysis of variance (ANOVA) with least significant difference (LSD), and P-values less than 0.05 were considered statistically significant.

\section{Results}

Effect of electron beam radiation on male germ cell development

Electron beam radiation (e.g., 6, 8, 10, or 12 Gy) was locally applied in a single dose to the testes of New Zealand White rabbits. An additional control group did not receive radiation. Testes sections from the control group exhibited normal spermatogenesis and an orderly arrangement of seminiferous epithelium over the 12 weeks of observation following irradiation (e.g., the experimental period). In contrast, sections from the treatment groups exhibited reduced spermatogenesis and distortion of tubular architecture. Moreover, the decrease in spermatogenesis was dose-dependent, with the greatest affects on spermatogenesis associated with the strongest irradiation dose (Figure 1). In contrast, Sertoli and Leydig cells appeared unaffected. RHST (Table 1) were also calculated based on the percentage of spermatogenesis stages that were observed to be affected. Values of RHST for the various treatment groups versus the control groups are presented in Figure 2 .
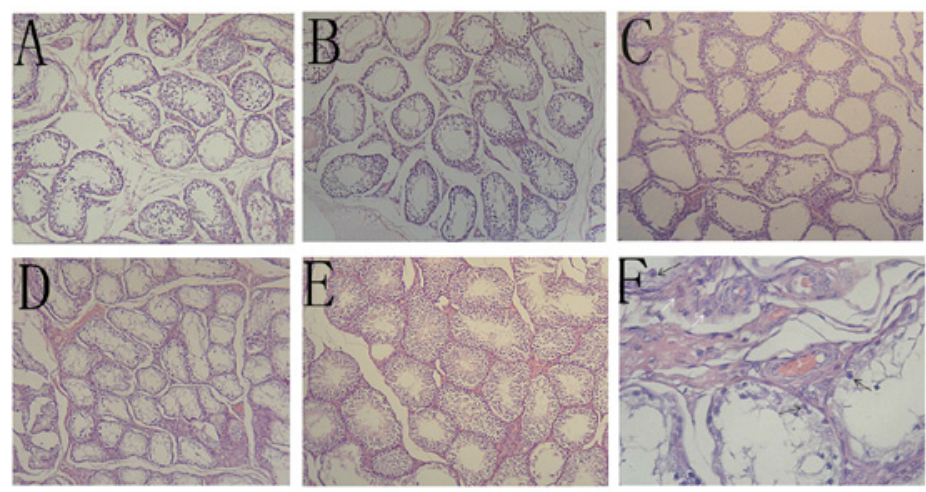

FIGURE 1 - Histological appearance of irradiated and age-matched, untreated control testes six weeks post-irradiation. (A-D) Representative images of tubule cross-sections following the local irradiation of testes with a single dose of $6 \mathrm{~Gy}, 8 \mathrm{~Gy}, 10 \mathrm{~Gy}$, or $12 \mathrm{~Gy}$, respectively. (E) A representative image of a tubule cross section from the control group (0 Gy). Control group sections showed normal spermatogenesis and an orderly arrangement of seminiferous epithelium. In contrast, the experimental groups exhibited a dose-dependent reduction in spermatogenesis and distortion of tubular architecture (Magnification 10×). F) Representative image of Sertoli cells (indicated with yellow arrows) and Leydig cells (indicated with green arrows) that were unaffected by 12 Gy irradiation (Magnification 40×).

TABLE 1 - Rates of hollow seminiferous tubules observed post-irradiation.

\begin{tabular}{|c|c|c|c|c|c|}
\hline Group & 2 weeks & 4 weeks & 6 weeks & 8 weeks & 12 weeks \\
\hline 0 Gy & $\begin{array}{c}0 \\
\text { bcde }\end{array}$ & $\begin{array}{c}0 \\
\text { bcde }\end{array}$ & $\begin{array}{c}0 \\
\text { bcde }\end{array}$ & $\begin{array}{c}0 \\
\text { bcde }\end{array}$ & $\begin{array}{c}0 \\
\text { cde }\end{array}$ \\
\hline $6 \mathrm{~Gy}$ & $\begin{array}{c}32.3 \pm 4.2 \\
\text { acde } \\
\text { BCDE }\end{array}$ & $\begin{array}{c}26.8 \pm 4.5 \\
\text { acde } \\
\text { ACDE }\end{array}$ & $\begin{array}{c}9.8 \pm 1.2 \\
\text { acde } \\
\mathrm{ABDE}\end{array}$ & $\begin{array}{c}5.2 \pm 0.6 \\
\text { acde } \\
\mathrm{ABC}\end{array}$ & $\begin{array}{c}2.5 \pm 0.8 \\
\text { cde } \\
\mathrm{ABC}\end{array}$ \\
\hline 8 Gy & $\begin{array}{c}47.8 \pm 4.9 \\
\text { abde } \\
\text { BCDE }\end{array}$ & $\begin{array}{c}42.7 \pm 6.3 \\
\text { abde } \\
\text { ACDE }\end{array}$ & $\begin{array}{c}24.2 \pm 4.2 \\
\text { abde } \\
\text { ABDE }\end{array}$ & $\begin{array}{c}11.8 \pm 2.2 \\
\text { abde } \\
\mathrm{ABC}\end{array}$ & $\begin{array}{c}10.5 \pm 2.2 \\
\text { abde } \\
\mathrm{ABC}\end{array}$ \\
\hline $10 \mathrm{~Gy}$ & $\begin{array}{c}62.7 \pm 3.6 \\
\text { abc } \\
\text { BCDE }\end{array}$ & $\begin{array}{c}68.5 \pm 3.7 \\
\text { abce } \\
\mathrm{ACDE}\end{array}$ & $\begin{array}{c}77.3 \pm 4.1 \\
\text { abce } \\
\mathrm{AB}\end{array}$ & $\begin{array}{c}78.2 \pm 4.6 \\
\text { abce } \\
\mathrm{AB}\end{array}$ & $\begin{array}{c}77.7 \pm 3.3 \\
\text { abce } \\
\mathrm{AB}\end{array}$ \\
\hline $12 \mathrm{~Gy}$ & $\begin{array}{c}67.5 \pm 5.2 \\
\text { abc } \\
\mathrm{BCDE}\end{array}$ & $\begin{array}{c}84.8 \pm 4.2 \\
\text { abcd } \\
\text { ACDE }\end{array}$ & $\begin{array}{c}89.3 \pm 2.2 \\
\text { abcd } \\
\text { AB }\end{array}$ & $\begin{array}{c}93.2 \pm 2.2 \\
\text { abcd } \\
\mathrm{AB}\end{array}$ & $\begin{array}{c}93.8 \pm 1.8 \\
\text { abcd } \\
\mathrm{AB}\end{array}$ \\
\hline
\end{tabular}

a: compared with control group, $\mathrm{P}<0.05$; b: compared with 6 Gy group, $\mathrm{P}<0.05$; c: compared with 8 Gy group, $\mathrm{P}<0.05$; d: compared with 10 Gy group, $\mathrm{P}<0.05$; e: compared with 12 Gy group, $\mathrm{P}<0.05$.

A: compared with 2 week time point, $\mathrm{P}<0.05$; B: compared with 4 week time point, $\mathrm{P}<0.05$; $\mathrm{C}$ : compared with 6 week time point, $\mathrm{P}<0.05$; $\mathrm{D}$ : compared with 8 week time point, $\mathrm{P}<0.05$; E: compared with 12 week time point, $\mathrm{P}<0.05$. 


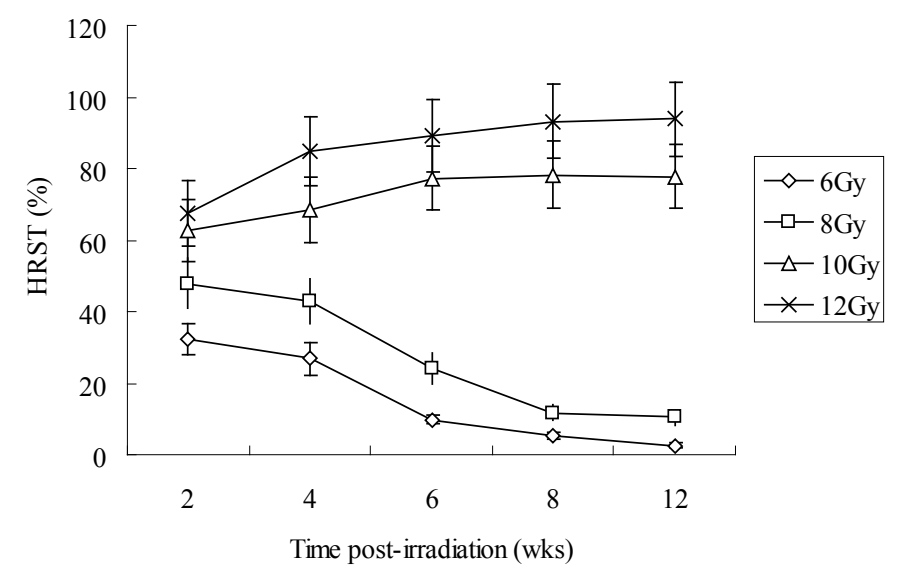

FIGURE 2 - RHST for rabbit testes evaluated at the post-irradiation time points indicated.

RHST detected following administration of different doses of irradiation

After two, four, six, and eight weeks post-irradiation, RHST showed significant differences between the treatment groups, except for the 10 Gy and 12 Gy groups at two weeks, and the 6 Gy group and the control group at 12 weeks. However, in general, RHSTs were observed to increase with stronger irradiation doses.

Comparisons were also made within each treatment group following irradiation. For example, of the rabbits that received a single dose of 6 Gy, RHST decreased following treatment, with significant differences observed two, four, six, and eight weeks post-irradiation. No further decreases were observed up to 12 weeks (e.g., the end of the experimental period). For the 8 Gy treatment group, no statistical differences in RHST for weeks 2 and 4 post-irradiation were observed, or between weeks 8 and 12 . However, these two periods were significantly different from the RHST recorded for week 6. In addition, the RHST for week 6 was statistically higher than the RHST for weeks 2 and 4 for both the 10 Gy and 12 Gy treatment groups. There was no significant difference between the RHST for week 6 and weeks 8 and 12 postirradiation.

\section{Effect of local irradiation on BMSCs}

There were no obvious differences in BMSC cell morphology for the 12 Gy treatment group (D) versus the control group (E). Accordingly, all isolated BMSCs appeared rounded in shape for the first two days of culturing. By day 3, BMSCs were spindle-shaped, round, or polygonal in shape. After one week,
BMSCs were homogenous in appearance, with almost all having a spindle-shape (Figure 3). Within two weeks, cultured BMSCs had proliferated to reach $80-90 \%$ confluence. Therefore, the shape of the proliferation curves obtained had an inverted "S" shape (Figure 4 ), based on the slow proliferation that occurred 0-2 days after inoculation, followed by a period of exponential growth over days $8-13$. Consistent with the morphology of the 12 Gy-treated cells versus control cells, the rates of cell proliferation were also found to be similar for cells from group D versus group E (Figure 4).

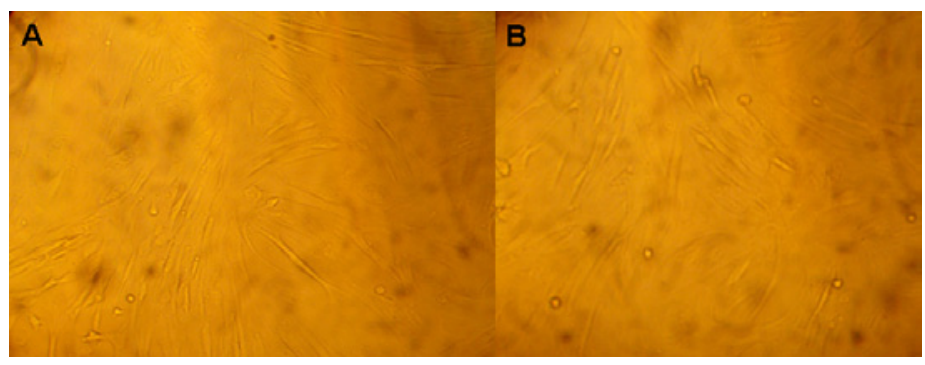

FIGURE 3 - Morphology of cultured BMSCs after two weeks of culturing. A monolayer of spindle-shaped cells was observed for both 12 Gy-treated cells (A) and control cells (B) (Magnification 20×).

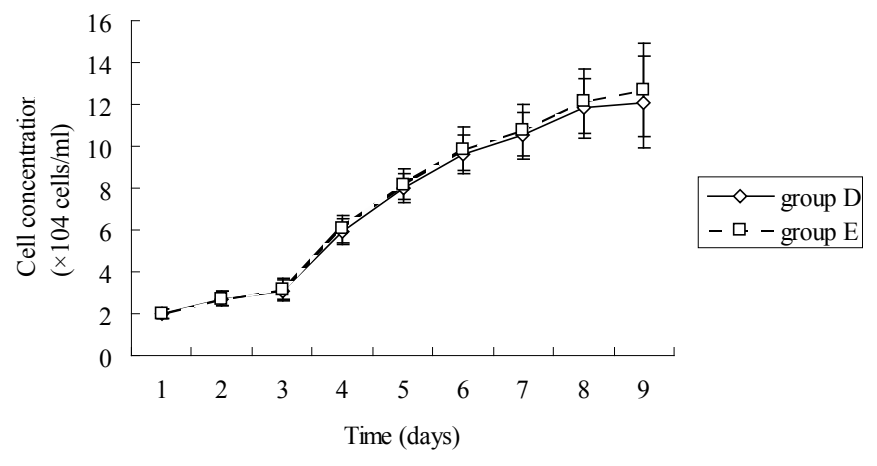

FIGURE 4 - Growth curves for the 3rd passage of BMSCs obtained following treatment with 12 Gy (group D) and control cells (group E).

\section{Discussion}

Stem cells derived from bone marrow are a population of adult pluripotent stem cells which can be induced into a spermatogonial stem cell-like population ${ }^{6-8,10,11}$. Recently, the use of BMSCs for an intratestical transplantation applied with allograft, or heterograft, was reported ${ }^{6,8}$. However, an autotransplantation had not been achieved. Autografts of BMSCs for an intratesticular transplant would represent a suitable clinical treatment for infertile men that want to have a genetically related child. Moreover, the approach would have ethical advantages over other strategies. A successful autologous transplantation is largely dependent on the preparation of recipients, which involves the destruction of endogenous germ cells and a blockade of spermatogenesis, 
respectively. The method then allows transplanted BMSCs to translocate from the rete testis to the basal compartment of the seminiferous tubules in order to restore spermatogenesis.

Rabbits are an experimental model commonly used to study the effects of applying autologous BMSCs. Accordingly, methods for the isolation and culturing of BMSCs have been described, as well as the capacity for BMSCs to regenerate myocardial ${ }^{13}$, bone, or cartilage ${ }^{14}$ tissue by trans-differentiation. Rabbits as an experimental model also provide a moderate body size, a docile temper, and they are convenient to raise, are modestly priced, and are easy to obtain. Specifically for reproductive toxicology research, male rabbits provide the following advantages $\left.{ }^{15}: 1\right)$ the male rabbit is the smallest, least expensive animal that can be ejaculated with an artificial vagina, permitting longitudinal evaluation of semen; 2) normal reproductive processes, including their associated morphology, the cycle of spermatogenic epithelium, and testicular maturation, can be studied. The sexual maturity of rabbits in temperate climates is also reached at 32 weeks. In contrast, a young buck under similar conditions can be used for reproduction from the age of 20 weeks $^{16}$. In the present study, 5-month-old male New Zealand White rabbits were used.

Techniques that have been used to reduce, or deplete, endogenous male germ cells in recipients include: irradiation ${ }^{17}$, chemotherapeutic drugs ${ }^{18}$, cold ischemia treatment ${ }^{19}$, and heating shock $^{20}$. Focal irradiation and chemotherapeutic drugs represent two additional techniques that are widely used. For example, local beam irradiation of the testes of domestic cats ${ }^{21}, \operatorname{dog}^{22}$, and sheep $^{23}$ has proven to be an effective technique for the preparation of recipients without inducing systemic effects. Based on the variables of species, dosage, regimen, and age that can affect the long-term outcome of irradiation, four doses were selected for the local irradiation of testes in the present study (e.g., 6, 8, 10, 12 Gy). The seminiferous epithelium that was irradiated with 6 Gy or 8 Gy exhibited the most serious injury two and four weeks post-treatment, with recovery observed after week 4 . In contrast, damage to the seminiferous epithelium was observed to increase up to six weeks after treatment with $10 \mathrm{~Gy}$ and $12 \mathrm{~Gy}$. Although after week 6, damage was not observed to increase or decrease. For Sertoli cells and Leydig cells, normal morphology for each cell type was observed following all treatments. This observation is consistent with the absence of damage to the supporting niche which is needed by spermatogonial stem cells. The RHST 6 weeks after treatment with 12 Gy were the highest of all the treatment groups, and were greater than $90 \%$. These results indicate that a single dose of $12 \mathrm{~Gy}$ is sufficient to prepare 5-month-old male rabbits as recipients, and that at least six weeks post-irradiation is needed for stem cell grafts to be administered. Accordingly, the first mating of normal male rabbits should be timed for an age of 135-140 days ${ }^{16}$.

Culturing of rabbit BMSCs four weeks after rabbit testes were locally treated with varying doses of irradiation up to 12 Gy, demonstrated that no significant effect on the growth and morphology of BMSCs had occurred relative to the normal control group.

\section{Conclusion}

The protocol tested in this study can prepare recipient rabbits suitable for the autologous transplantation of bone marrow stem cells, thereby providing a model with which to explore treatments for testical infertility.

\section{References}

1. Leifke E, Nieschlag E. Male infertility treatment in the light of evidence-based medicine. Andrologia. 1996;28 Suppl 1:23-30.

2. de Kretser DM, Baker HW. Infertility in men: recent advances and continuing controversies. J Clin Endocrinol Metab. 1999;84:344350 .

3. Matzuk MM, Lamb DJ. The biology of infertility: research advances and clinical challenges. Nat Med. 2008;14:1197-213.

4. Brinster RL, Avarbock MR. Germline transmission of donor haplotype following spermatogonial transplantation. Proc Natl Acad Sci, 1994;91:11303-7.

5. Herzog EL, Chai L, Krause DS. Plasticity of marrow-derived stem cells. Blood. 2003;102:3483-93.

6. Nayernia K, Lee JH, Drusenheimer N. Derivation of male germ cells from bone marrow stem cells. Lab Invest. 2006;86:654-63.

7. Drusenheimer N, Wulf G, Nolte J, Lee JH, Dev A, Dressel R, Gromoll J, Schmidtke J, Engel W, Nayernia K. Putative human male germ cells from bone marrow stem cells. Soc Reprod Fertil Suppl, 2007;63:69-76.

8. Lue Y, Erkkila K, Liu PY, Ma K, Wang C, Hikim AS, Swerdloff RS. Fate of bone marrow stem cells transplanted into the testis: potential implication for men with testicular failure. Am J Pathol. 2007; 170:899-908.

9. Zheng YH, Jiang LH, Zhang ZG, Su K, Kuang SJ. Growth characteristics of basic fibroblast growth factor gene-transfected bone marrow mesenchymal stem cells seeded on coral skeleton in vitro. J Clin Rehab Tiss Eng Res. 2009;21:4105-8.

10. Hua J, Pan S, Yang C, Dong W, Dou Z, Sidhu KS. Derivation of male germ cell-like lineage from human fetal bone marrow stem cells. Reprod Biomed Online. 2009;19:99-105.

11. Horn MM, Paz AH, Duarte ME, Baldo G, Belardinelli MC, Matte U, Lima EO, Passos EP. Germinative testicular cells and bone marrow mononuclear cells transplanted to a rat model of testicular degeneration. Cloning Stem Cells. 2008;10:543-6.

12. Mertes H, Pennings G. Ethical aspects of the use of stem cell derived gametes for reproduction. Health Care Anal. 2010;18:267-78.

13. Chen YJ, Liu W, Li WM, Gao C. Autologous bone marrow mesenchymal cell transplantation improves left ventricular function in a rabbit model of dilated cardiomyopathy. Exp Mol Pathol. 2010;88:311-5. 
Preparation of infertile male rabbits by local electron beam irradiation for intratesticular transplantation of autologous bone marrow stem cells

14. Im GI, Kim DY, Shin JH, Hyun CW, Cho WH. Repair of cartilage defect in the rabbit with cultured mesenchymal stem cells from bone marrow. J Bone Joint Surg. 2001;83:289-94.

15. Morton D. The use of rabbits in male reproductive toxicology. Environ Health Perspect. 1988;77:5-9.

16. Lebas F, Coudert P, Rochambeau H de, Thébault RG. Reproduction. The rabbit: husbandry, health and production (new revised version). FAO 1997.

17. van Beek ME, Meistrich ML, de Rooij DG. Probability of selfrenewing division of spermatogonial stem cells in colonies, formed after fission neuron irradiation. Cell Tissue Kinet. 1990;23:1-16.

18. Brinster CJ, Ryu BY, Avarbock MR, Karagenc L, Brinster RL, Orwig KE. Restoration of fertility by germ cell transplantation requires effective recipient preparation. Biol Reprod. 2003;69:41220.

19. Young GP, Goldstein M, Phillips DM, Sundaram K, Gunsalus GL, Bardin CW. Sertoli cell-only syndrome produced by cold testicular ischemia. Endocrinology. 1988;122:1074-82.

20. Ma W, An L, Wu Z, Wang X, Guo M, Miao K, Ma W, Tian J. Efficient and safe recipient preparation for transplantation of mouse spermatogonial stem cells: pretreating testes with heat shock. Biol Reprod. 2011;85:670-7.

21. Kim Y, Selvaraj V, Dobrinski I, Lee H, McEntee MC, Travis AJ. Recipient preparation and mixed germ cell isolation for spermatogonial stem cell transplantation in domestic cats. J Androl. 2006;27:248-56.

22. Kim Y, Turner D, Nelson J, Dobrinski I, McEntee M, Travis AJ. Production of donor-derived sperm after spermatogonial stem cell transplantation in the dog. Reproduction. 2008;136:823-31.

23. Herrid M, Olejnik J, Jackson M, Suchowerska N, Stockwell S, Davey R, Hutton K, Hope S, Hill JR. Irradiation enhances the efficiency of testicular germ cell transplantation in sheep. Biol Reprod. 2009;81:898-905.

\section{Acknowledgements}

This study is supported by Hebei Population and Family Planning committee. We are grateful to Fan Cai, Li Heng, and Radiotherapeutic Centre of Bethune International Peace hospital attached to PLA for their skillful technical assistance in performing irradiation treatment with local electron beam. We thank An Jie, Liu Liang, and the Pathology Department of Bethune International Peace hospital attached to PLA for their assistance in performing the histological aspects.

\section{Correspondence:}

\section{Prof Wen-Qing Cai}

Department of Urology

The Second Hospital of Heibei Medical University

Shijiazhuang 050000, China

cai_prof@yeah.net

Prof Jian-Hong Qiu

Department of Urology

Bethune International Peace Hospital

Shijiazhuang 050082, China

qiujh2755@sohu.com

Received: September 25, 2012

Review: November 26, 2012

Accepted: December 20, 2012

Conflict of interest: none

Financial source: none

${ }^{1}$ Research performed at Stem Cells Research Center, Department of Blood Transfusion, Bethune International Peace Hospital, Shijiazhuang, China. 